\title{
Divertículo esofágico secundario a peristalsis hipertensiva severa
}

\author{
Esophageal diverticulum secondary to severe hypertensive peristalsis
}

Marta González-Andaluz, María José Fernández-Díaz y

María Soledad Trugeda-Carrera

Varón de 57 años, sin antecedentes de interés, remitido a consulta de Cirugía General desde Digestivo por regurgitación nocturna y tos. En tránsito esófago-gastrointestinal se evidencia divertículo esofágico en tercio inferior (Figura 1), y en la gastroscopia, a $45 \mathrm{~cm}$ de arcada dentaria, se visualiza un divertículo de gran tamaño. Se completa estudio con manometría, que pone de manifiesto una peristalsis esofágica severa y TC toracoabdominal, que confirma la presencia de un divertículo esofágico de $5 \times 4 \times 5 \mathrm{~cm}$ en tercio inferior (Figura 2). Ante estos hallazgos y la sintomatología del paciente, se decide realizar diverticulectomía + miotomía esofágica.

\section{Responsabilidades éticas}

Protección de personas y animales. Los autores declaran que para esta investigación no se han realizado experimentos en seres humanos ni en animales.

Confidencialidad de los datos. Los autores declaran que han seguido los protocolos de su centro de trabajo sobre la publicación de datos de pacientes.

Derecho a la privacidad y consentimiento informado. Los autores declaran que en este artículo no aparecen datos de pacientes.

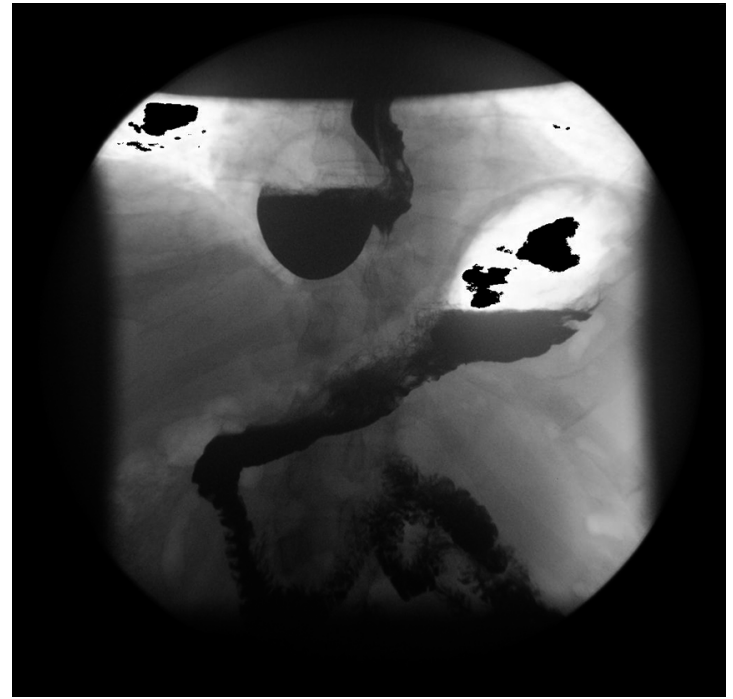

ospital Universitario Marqués de Valdecilla. Santander, España.

Recibido el 12 de agosto de 2018 y aceptado para publicación el 8 de septiembre de 2018.

Correspondencia a: Dra. Marta González-Andaluz mgandaluz@hotmail.com
Figura 1. Tránsito que muestra divertículo.

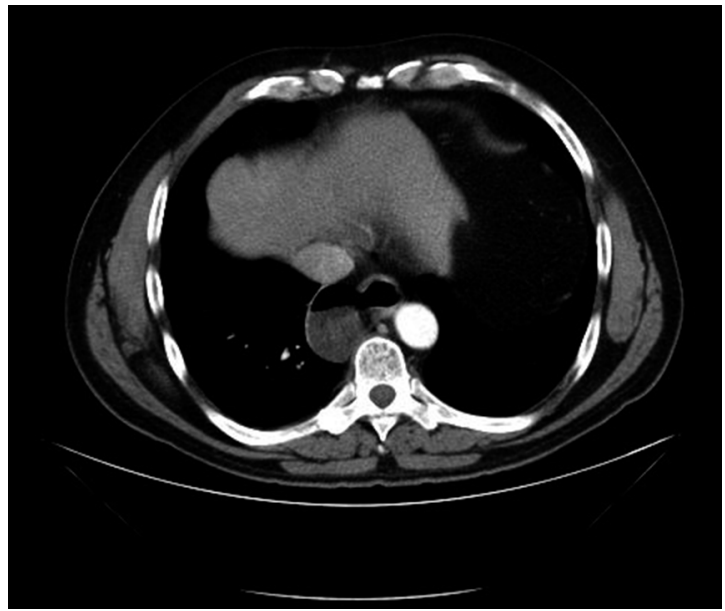

Figura 2. TC que muestra divertículo. 